\title{
Growth Kinetics and Corrosion Protection Properties of Plasma Electrolytic Oxidation Coatings on Biodegradable Mg2\% Sr Alloy \\ DOI:
}

10.3103/S1068375520010111

\section{Document Version}

Accepted author manuscript

Link to publication record in Manchester Research Explorer

Citation for published version (APA):

Lazarev, D. M., Farrakhov, R. G., Mukaeva, V. R., Kulyasova, O. B., Parfenov, E. V., \& Yerokhin, A. L. (2020). Growth Kinetics and Corrosion Protection Properties of Plasma Electrolytic Oxidation Coatings on Biodegradable Mg2\% Sr Alloy. Surface Engineering and Applied Electrochemistry, 56(1), 83-92.

https://doi.org/10.3103/S1068375520010111

\section{Published in:}

Surface Engineering and Applied Electrochemistry

\section{Citing this paper}

Please note that where the full-text provided on Manchester Research Explorer is the Author Accepted Manuscript or Proof version this may differ from the final Published version. If citing, it is advised that you check and use the publisher's definitive version.

\section{General rights}

Copyright and moral rights for the publications made accessible in the Research Explorer are retained by the authors and/or other copyright owners and it is a condition of accessing publications that users recognise and abide by the legal requirements associated with these rights.

\section{Takedown policy}

If you believe that this document breaches copyright please refer to the University of Manchester's Takedown Procedures [http://man.ac.uk/04Y6Bo] or contact uml.scholarlycommunications@manchester.ac.uk providing relevant details, so we can investigate your claim.

\section{OPEN ACCESS}




\title{
Growth Kinetics and Corrosion Protection Properties of Plasma Electrolytic Oxidation Coatings on Biodegradable Mg-2\% Sr Alloy
}

\author{
D. M. Lazarev ${ }^{a,{ }^{*}}$, R. G. Farrakhov ${ }^{a}$, V. R. Mukaeva ${ }^{a}$, O. B. Kulyasova ${ }^{a}$, E. V. Parfenov ${ }^{a}$, and A. L. \\ Yerokhin $^{b}$ \\ a - Ufa State Aviation Technical University, Ufa, Bashkortostan, 450008 Russia \\ $b$ - University of Manchester, Manchester, M13 9PL UK \\ *e-mail: denis_rb84@mail.ru
}

\begin{abstract}
The growth kinetics of plasma electrolytic oxidation coatings on biodegradable $\mathrm{Mg}-2 \% \mathrm{Sr}$ alloy with coarse- and ultrafine-grain structures was evaluated. The parameters characterizing the coating growth kinetic were estimated for the alloys with different structures on the basis of a dissolution/deposition model, and their correlation with the coating properties was demonstrated. The coating morphology and phase composition were related to the protective properties of the alloys and investigated electrochemically in the Ringer's solution, using uncoated and coated samples. Equivalent circuits modeling "alloy-electrolyte" and "alloy-coating-electrolyte" systems were developed. The PEO coating produced on the alloy with the ultrafine grain structure displayed the best protective properties.
\end{abstract}

Keywords: plasma electrolytic oxidation, coating growth kinetics, biodegradable alloy, corrosion, equivalent circuit 


\section{INTRODUCTION}

The binary alloy $\mathrm{Mg}-2 \% \mathrm{Sr}$ shows potential for the production of biodegradable traumatology implants that may replace the widely used temporary titanium implants that must be removed from the body after the bone tissue repair is complete. The $\mathrm{Mg}-2 \% \mathrm{Sr}$ alloy contains $\mathrm{Sr}$ as a doping element, and the indicated doping level ensures that the alloy's mechanical properties remain at an acceptable level during osteosynthesis [1]. As with other magnesium alloys, the Young modulus of this alloy is similar to that of the human bone [2]. However, it exhibits low ductility and high rate of dissolution in the corrosive medium of the human body, which limits its use for implant design. The high dissolution rate of the magnesium alloy can be explained by the fact that the Pilling-Bedworth ratio for magnesium is below unity. This means that the metal does not develop a continuous surface oxide film in a corrosive medium, e.g., a physiological solution. Magnesium, therefore, undergoes rapid destruction, with a much higher dissolution rate compared to the rate of the bone repair [3]. Modifying the surface of magnesium implants by plasma electrolytic oxidation (PEO) may be a promising approach to resolve this issue [4].

PEO is an electrochemical processing technique in which the anode surface under modification develops a protective oxide layer that inhibits corrosion and enables control over the biodegradation rate. In contrast to the conventional treatment techniques, in PEO, a complex set of electrochemical processes occurs [4], and their kinetics affects not only the growth of the oxide layer but also its resulting corrosion properties. It should be pointed out that the kinetic aspects of the oxide coating growth during PEO in general and for the PEO of the $\mathrm{Mg}-2 \% \mathrm{Sr}$ alloy in particular has not yet been sufficiently studied. In addition, recently, different methods have been used to improve the ductility of magnesium alloys. In those based on thermomechanical treatment, including severe plastic deformation, the alloy structure is modified by reducing the grain size and creating special distribution of the secondary phases. These methods enable us to achieve deep structural transformations, dramatic reduction in the size of phase components, and modification of the alloy texture. In this study, we used high pressure torsion (HPT) [5], a severe plastic deformation technique, to increase the ductility of the $\mathrm{Mg}-2 \% \mathrm{Sr}$ alloy. We note that the ultra-fine grain (UFG) structure of the $\mathrm{Mg}-2 \% \mathrm{Sr}$ alloy produced by reducing the grain size using HPT followed by annealing at a temperature of $200^{\circ} \mathrm{C}$ features a fairly high ductility [5].

The aim of this work is to perform quantitative evaluation of the growth kinetics of PEO coatings fabricated on the biodegradable coarse-grain (CG) and ultrafine-grain (UFG) Mg- $2 \% \mathrm{Sr}$ alloys and to explore the correlation between the coating growth kinetics and the protective properties of the coatings.

\section{EXPERIMENTAL}

\section{Modification of the Alloy Structure}

CG samples were prepared by subjecting cast samples of the alloy under study to homogenization annealing at $450^{\circ} \mathrm{C}$ for $20 \mathrm{~h}$. To prepare the UFG samples, the alloy was first subjected to HPT. To do this, samples $20 \mathrm{~mm}$ in diameter and $2 \mathrm{~mm}$ in thickness were subjected to a torsional load while under high pressure $(6 \mathrm{GPa})$ at room temperature. The HPT procedure was described in more detail [5]. Additionally, the samples that undergone HPT treatment were thermally annealed at $T=200^{\circ} \mathrm{C}$ for $1 \mathrm{~h}$, followed by cooling in water to stabilize their UFG structure. All thermal treatment procedures were carried out in air using a Nabertherm furnace. 


\section{PEO Treatment}

PEO treatment was performed on disk-shape alloy samples, $20 \mathrm{~mm}$ in diameter and $2 \mathrm{~mm}$ thick, in a calcium-phosphate electrolyte composed of Na3PO4.12H2O (12 g/L) and $\mathrm{Ca}(\mathrm{OH}) 2(2 \mathrm{~g} / \mathrm{L})$ [6].The coatings were fabricated in the pulsed unipolar mode with voltage control, and the duration of the PEO treatment was $10 \mathrm{~min}$. The sample was connected as the anode, and square voltage pulses were applied; the earthed electrolyzer bath was the cathode. The electrolyte temperature was maintained at $20 \pm 1^{\circ} \mathrm{C}$. In the experiments, the current and voltage were recorded continuously at a sampling rate of $1 \mathrm{MHz}$, while the electrolyte temperature was monitored and recorded with a period of $1 \mathrm{~s}$. The pulsed voltage parameters are listed in Table 1.

\section{Surface Characterization}

The microstructure of the alloy and the coatings were investigated using a JEM-6390 scanning electron microscope (SEM) and JEM-2100 transmission electron microscope (TEM). The structure of the $\mathrm{Mg}-2 \% \mathrm{Sr}$ alloy was exposed using an etching solution composed of picric acid (2.5 $\mathrm{mg}$ ), acetic acid $(2.5 \mathrm{~mL})$, distilled water $(5 \mathrm{~mL})$, and ethanol $(50 \mathrm{~mL})$. The average grain size was calculated by the intercept method. We analyzed 300 grains of each type of the grain structures under discussion using ImageJ software. The thickness of the oxide layer was measured using an eddy current gauge for dielectric coatings Defelsko Positector 6000 with N-type sensor for nonmagnetic substrates. The elemental analysis of the coatings was performed on a Shimadzu EDX-800P X-ray fluorescence spectrometer. The phase composition analysis was performed on a Rigaku Ultima IV X-ray diffractometer using CuKa radiation. The coating porosity was calculated from the SEM images using ImageJ software.

\section{Electrochemical Tests}

Electrochemical tests were carried out in a Ringer's solution with pH 7.4 (matching the hysiological medium of the human body) on an Elins P-5X potentiostat/galvanostat/impedance analyzer (Russia). Measurements were carried out at $37.0 \pm 0.1^{\circ} \mathrm{C}$ in a three-electrode cell $(80 \mathrm{~mL})$ with a Pt counterelectrode and a silver/silver chloride reference electrode. The open circuit potential was measured during the first $2 \mathrm{~h}$, a time period required for the sample surface to achieve a steady state, and electrochemical impedance spectroscopy (EIS) measurements in the frequency range of $100 \mathrm{kHz}$ to 1 $\mathrm{MHz}$ were taken thereafter. After the steady state was established, polarization curves were recorded by scanning the potential in the range of -300 to $+300 \mathrm{mV}$ with respect to the open circuit potential at a rate of $0.25 \mathrm{mV} / \mathrm{s}$. The corrosion current and potential were calculated from the Tafel regions of polarization curves [7]. Only the cathodic branch was used to calculate the Tafel slope, because the anodic branches of polarization curves for the magnesium alloys with PEO coatings do not typically exhibit linear behavior [6]. Equivalent circuits for "substrate-electrolyte" and "substrate -coating-electrolyte" systems were developed on the basis of the EIS measurements. The parameters of the circuit components were determined using ZView software (Scribner Associates), which enabled us to evaluate the corrosion behavior of the samples.

\section{RESULTS AND DISCUSSION}

\section{Surface Morphology}

The microstructure of the uncoated alloy sample with CG structure can be understood from Fig. 1a. We identified that the structure of the $\mathrm{Mg}-2 \% \mathrm{Sr}$ alloy subjected to the homogenization annealing 
consists of grains of the $\alpha-\mathrm{Mg}$ solid solution with the $\alpha-\mathrm{Mg}+\mathrm{Mg} 17 \mathrm{Sr} 2$ eutectics along the grain boundaries [5]. The average grain size was $85 \mu \mathrm{m}$, and the proportion of the eutectic phase was $20.9 \%$.

Table 1. Pulsed voltage parameters used in the PEO process

\begin{tabular}{c|l|c|c|c}
\hline \multirow{2}{*}{ No. } & \multirow{2}{*}{$\begin{array}{c}\text { Alloy } \\
\text { structure }\end{array}$} & \multicolumn{3}{|c}{ Pulsed voltage parameters } \\
\cline { 3 - 5 } & $\begin{array}{c}\text { amplitude } \\
U_{m}, \mathrm{~V}\end{array}$ & $\begin{array}{c}\text { frequency } \\
f, \mathrm{~Hz}\end{array}$ & $\begin{array}{c}\text { duty cycle } \\
d, \%\end{array}$ \\
\hline 1 & CG & 470 & 500 & 10 \\
\hline
\end{tabular}

The microstructure of the uncoated sample with the UFG structure is shown in Figs. $1 \mathrm{~b}$ and $1 \mathrm{c}$. The analysis of this sample established that the HPT treatment and additional thermal treatment gave rise to the UFG structure in which the mean grain size of the $\alpha-M g$ matrix was $850 \mathrm{~nm}$. Fine grains of the $\alpha-\mathrm{Mg}$ phase and a region of the eutectic phase can be seen in Fig. $1 \mathrm{~b}$. The eutectic phase volume fraction is slightly lower compared to the CG sample.
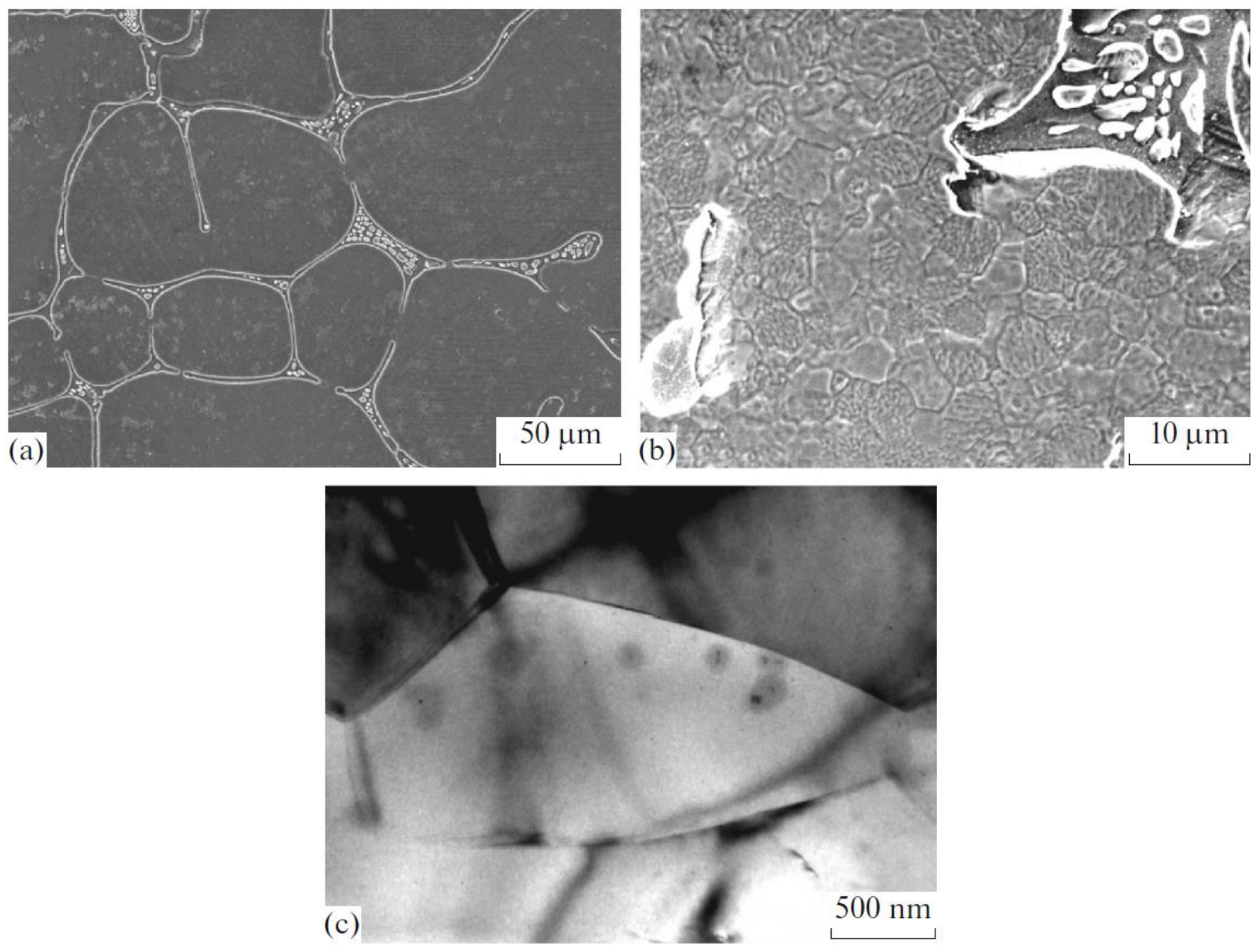

Fig. 1. Microstructure of coating-free alloy samples: (a) SEM image showing the CG structure, (b) SEM image showing the UFG structure, and (c) TEM image of the UFG structure.

Figure 2 shows SEM images of the coatings formed on the $\mathrm{Mg}-2 \% \mathrm{Sr}$ alloy. By investigating the surface morphology, we found that the coatings on the samples with CG and UFG structures had an 
inhomogeneous structure. Along with flat, dense regions, the coatings have a developed pore system typical to the PEO coatings. The porous morphology of the coatings can be explained by specific coated of the PEO mechanism: the surface layer of the metal undergoes intensive modification by numerous discharges that promote anodic dissolution of magnesium and formation of magnesium hydroxide that then deposits on the surface, and the coating undergoes re-melting. This is indicated by the presence of melted oxide craters formed around the pores in which the microdischarges occurred. The thickness $h$ of the coating produced on the sample with the CG structure is slightly less than that on the UFG sample, with the sample porosity $\Pi$ being the same on both sides of the coating (Table 2).
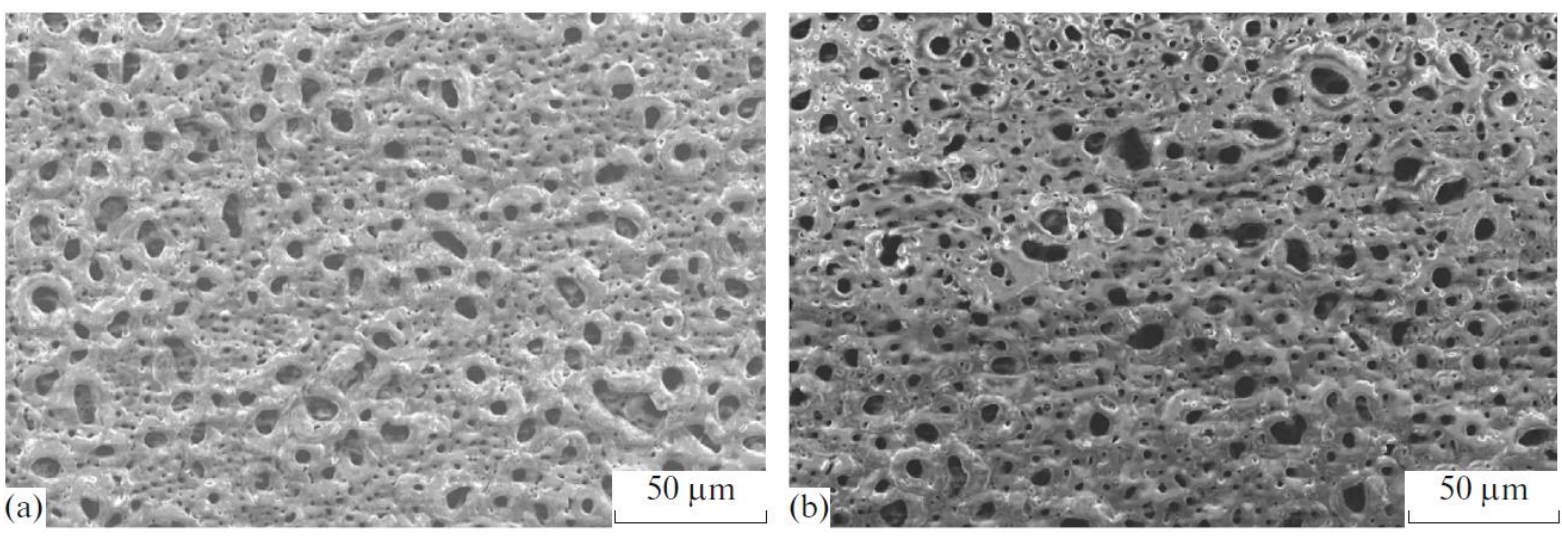

Fig. 2. SEM images of PEO coatings created on the alloy samples with (a) CG and (b) UFG structures.

Table 2. Properties of the PEO coatings and kinetic parameters of the PEO process

\begin{tabular}{l|c|c|c|c|c}
\hline \multicolumn{1}{c|}{ Alloy structure } & $h, \mu \mathrm{m}$ & $\Pi, \%$ & $i_{0}, \mathrm{~A} / \mathrm{cm}^{2}$ & $D \times 10^{-6}, \mathrm{~cm}^{2} / \mathrm{s}$ & $\tau, \mathrm{s}$ \\
\hline CG & $11.7 \pm 1.20$ & $22 \pm 2.0$ & $5.88 \pm 0.35$ & $12.12 \pm 0.33$ & $24.44 \pm 1.55$ \\
UFG & $14.1 \pm 1.50$ & $22 \pm 2.0$ & $6.05 \pm 0.44$ & $13.38 \pm 0.75$ & $13.20 \pm 1.25$ \\
\hline
\end{tabular}

\section{Quantitative Evaluation of the PEO Kinetics for the Mg-2\% Sr Alloy}

The key feature of the kinetics of electrochemical processes leading to the formation of a new phase is the variation of the reaction rate (i.e., current) over time at a given potential; this depends on the accumulation dynamic of the new phase and reflects the changing conditions on the surface [8]. In the PEO process, the oxide layer growth kinetics strongly depends on: (i) the nucleation rate of nuclei that then become the new phase and (ii) the rate of magnesium ion migration (diffusion) within the growing oxide film $[8,9]$. To study the kinetics of the PEO process, we can, therefore, use known electrochemical relaxation techniques in which the equilibrium state of the electrochemical system under study is perturbed by a stepwise input signal, and the subsequent relaxation of the system into the equilibrium state or a new steady state is registered [8]. In this work, we used chronoamperometry to quantitatively evaluate the growth kinetics of the PEO coatings [8]. In this method, the estimates of the kinetic coefficients are obtained by analyzing transient processes of the current density at the relaxation stage [8]. Herein, a voltage step is defined as a periodic sequence of voltage pulse amplitudes applied during the PEO process, Um(t); the constancy of the 
voltage amplitude for each pulse was controlled by the voltage source, while the amplitude values for the resulting current density jm(t), i.e., the system response, were registered [10].

Representative voltage pulses and corresponding current pulses are shown in Fig. 3, and the temporal variation of the average voltage per pulse and current density amplitude transients during the PEO treatment of the alloy under study are shown in Fig. 4. The current density registered in response to the application of the voltage step (in the sense defined above) decreased over the time range of 60-600 s (Fig. 5), which corresponds to the system relaxation. The current density decreased nonlinearly as the system achieved a new steady state showing the formation of the oxide film. Meanwhile, the rate of the oxide film growth diminished during the PEO process. For the quantitative evaluation of the PEO kinetics MATLAB software package was used; experimental data on the current density were fitted with the model shown below [9]:

$$
i=i_{0} e^{\frac{t^{m}}{\tau}}+z F c \sqrt{\frac{D}{\pi t}}\left(1-e^{-\frac{t^{m}}{\tau}}\right),
$$

where $i_{0}$ is the initial current density registered for the magnesium dissolution; $m$ is a factor determining the type of crystallization; $z$ is the nucleus charge; $F$ is the Faraday constant; $c$ is the magnesium concentration in growing oxide film; $D$ is the diffusion coefficient for the magnesium ions in the oxide film; $\tau$ is the time constant for a three-dimensional magnesium crystallization; and $t$ is time.
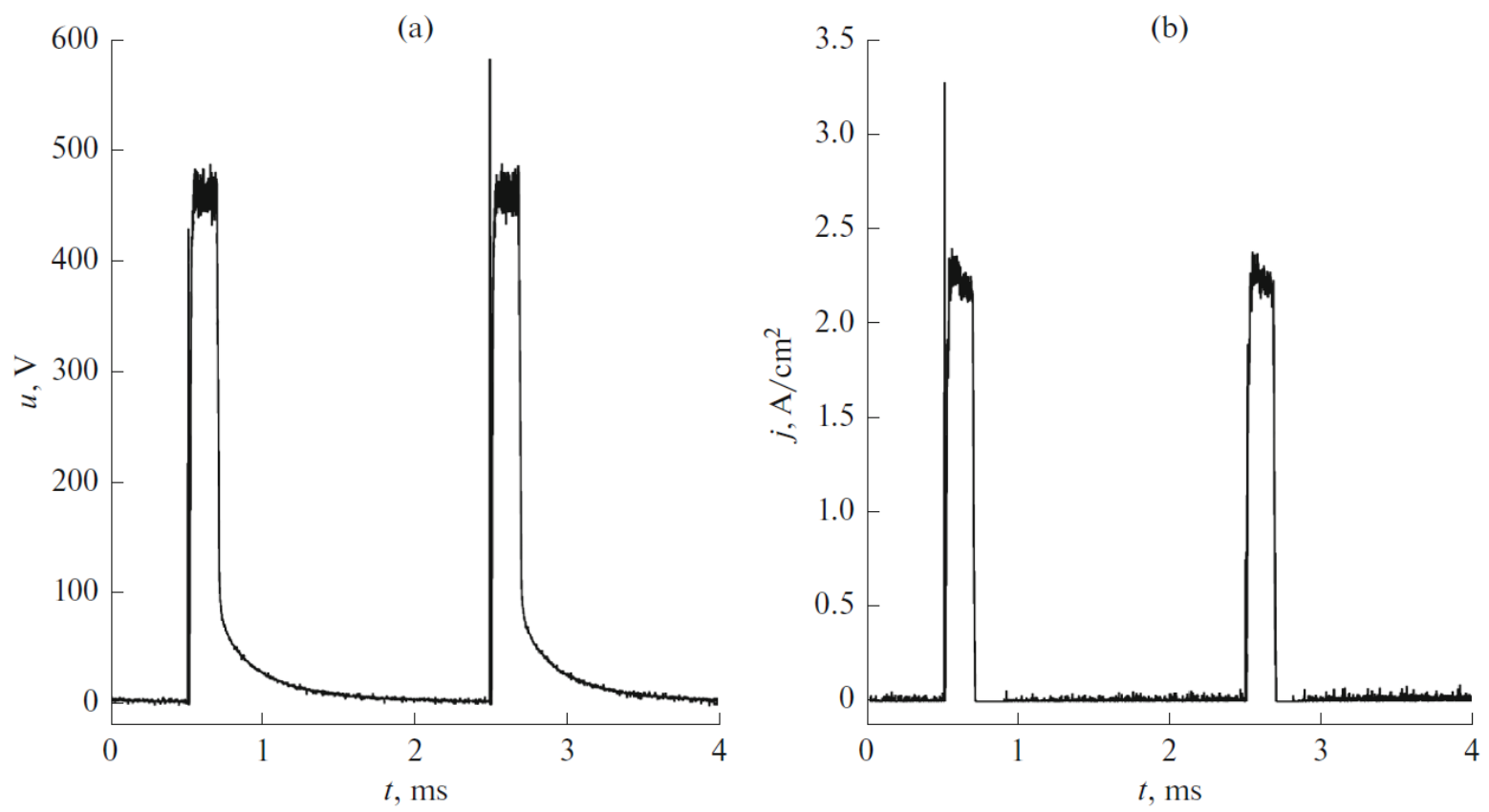

Fig. 3. Representative (a) voltage and (b) current density pulses recorded the 30th second during the PEO treatment of theMg-2\% Sr alloy with the CG structure.

The modeling of the experimental data yielded estimates of coefficients $i_{0}, D$, and $\tau$, which inform us on the kinetics of the electrochemical processes that occur as the system evolves toward a new equilibrium state during the PEO treatment of the magnesium alloy. Here, we put $m=1$, which corresponds to instantaneous three-dimensional crystallization $[8,9]$. The goodness of fit was 
assessed by the coefficient of determination $R^{2}$, and this was 0.99 . A result of modelling the current density is shown in Fig. 5.
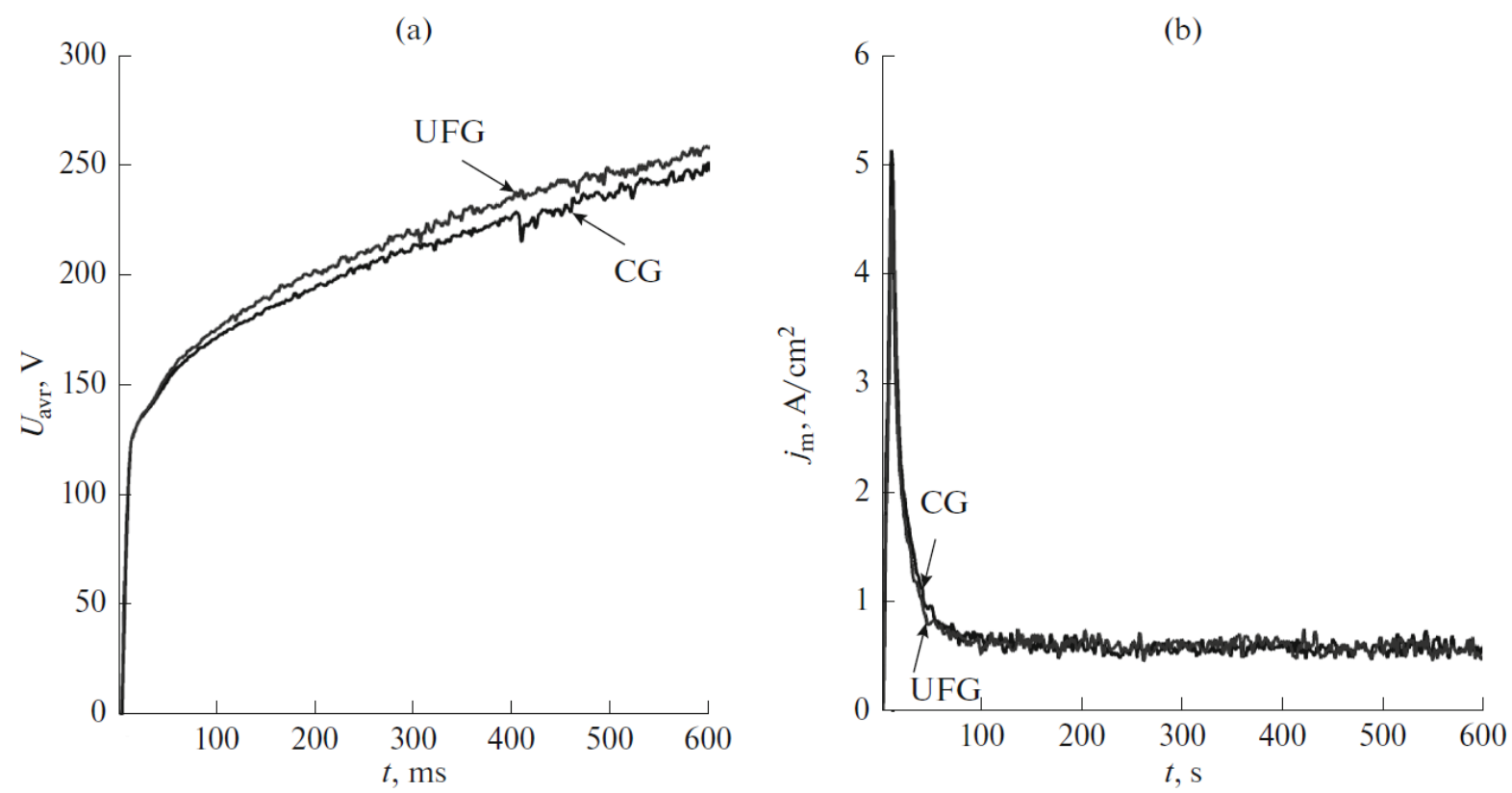

Fig. 4. Time-dependent variations of (a) the average voltage and (b) the current density amplitude during PEO treatment of the $\mathrm{Mg}-2 \% \mathrm{Sr}$ alloy.

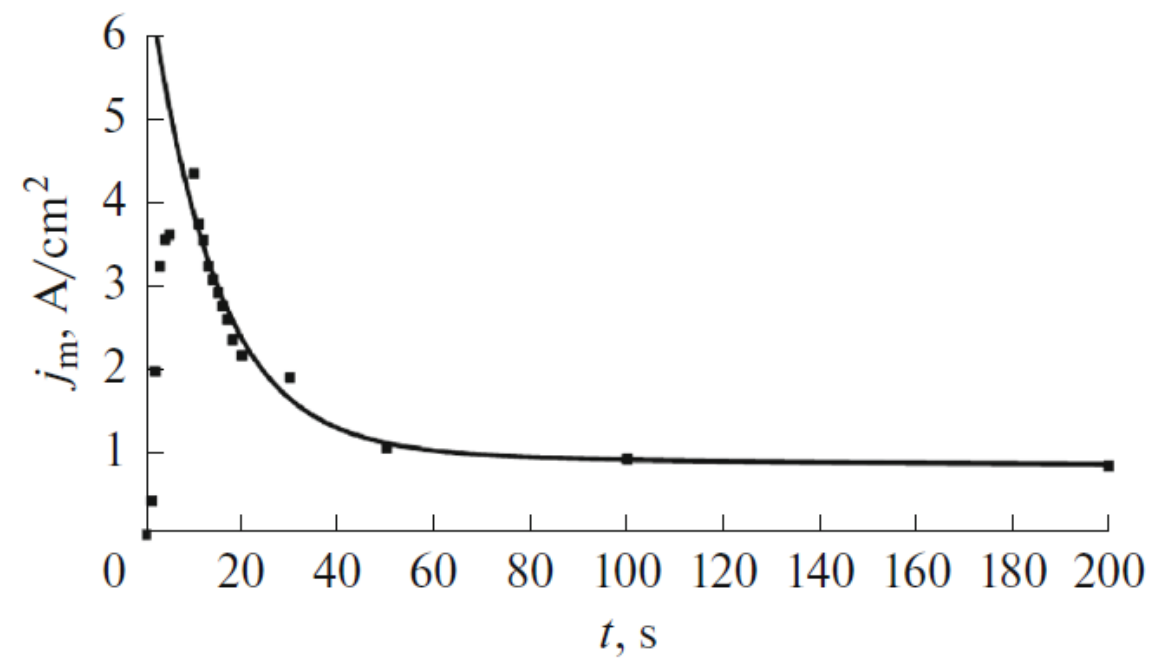

Fig. 5. Current density during PEO treatment of the Mg-2\% Sr alloy with UFG structure: experimental data and the modeling curve.

The values for the kinetic coefficients obtained from the data modeling are listed in Table 2. It can be seen (Table 2) that the initial current density of the magnesium dissolution is nearly the same for the both types of the alloy structure. This current density corresponds to the uncoated part of the surface, which was the same in all experiments. The values for parameter $D$ fall in the range of (12.0 $-13.5) \times 10-6 \mathrm{~cm} 2 / \mathrm{s}$. Meanwhile, the ion mobility was higher in the sample with UFG structure. The 
time constant $\tau$ characterizing three-dimensional crystallization ranged from 13.0 to $25.0 \mathrm{~s}$, with the UFG sample having lower $\tau$. By comparing the kinetic parameters with the coating properties (Table 2), we found that the coating on the sample with UFG structure is thicker than that on its CG counterpart because the $\mathrm{Mg}$ ion mobility is higher in the former. This is a valid comparison, because the coating porosity is the same for the both structural types of the substrate. This also does not contradict with the values for time constant of three dimensional crystallization, which are smaller for the UFG sample, indicating, therefore, that the coating forms faster on that sample, and it is thicker than on CG sample. These correlations are likely to be related to the fact that reduction in the grain size causes the nucleation rate to increase and promotes the growth of magnesium oxide crystals on the alloy crystal lattice, which is characterized by an elevated energy of the nonequilibrium structure. We can thus see that the differences identified between the kinetic parameters show that the nucleation rate and the magnesium ion diffusion coefficient in the growing oxide film depend on the substrate grain size, provided that the processing conditions are identical.

\section{Elemental and Phase Composition of the Coatings}

Energy-dispersive X-ray spectroscopy (EDX) showed that the analyzed coatings contained Ca and $\mathrm{P}$, which are biocompatible elements. The presence of $\mathrm{Sr}$ and $\mathrm{Mg}$ in the coatings was also established. The results of the elemental analysis of the PEO coatings are summarized in Table 3.

Table 3. Elemental composition of PEO coatings created on the $\mathrm{Mg}-2 \% \mathrm{Sr}$ alloy

\begin{tabular}{l|c|c|c|c|c}
\hline \multirow{2}{*}{ Alloy structure } & \multicolumn{5}{|c}{ Element, wt \% } \\
\cline { 2 - 6 } & $\mathrm{Mg}$ & $\mathrm{Sr}$ & $\mathrm{P}$ & $\mathrm{Ca}$ & other \\
\hline CG & $53.77 \pm 3.22$ & $7.48 \pm 1.15$ & $28.58 \pm 2.35$ & $5.38 \pm 0.92$ & $4.79 \pm 0.28$ \\
UFG & $62.22 \pm 3.15$ & $7.96 \pm 1.24$ & $22.50 \pm 2.05$ & $2.93 \pm 0.75$ & $4.39 \pm 0.44$ \\
\hline
\end{tabular}

The results of elemental analysis (Table 3 ) showed that samples with CG and UFG structures had nearly the same $\mathrm{Sr}$ content (wt \%). The Mg content (wt \%) was different in the samples with different structures: the coatings formed on the UFG sample had a greater Mg content (wt \%) than those on the CG sample. These observations are in line with the results of the quantitative evaluation of the PEO kinetics that showed that $\mathrm{Mg}$ ion diffusion coefficient in the growing coating is higher for the UFG sample.

The XRD patterns for the CG and UFG samples both without and with the coatings (the latter denoted CG + PEO and UFG + PEO) are shown in Fig. 6 . The analysis of the XRD patterns for the uncoated samples identified the presence of peaks corresponding to the substrate $(\mathrm{Mg})$ and the Mg17Sr2 secondary phase. For the samples with coatings, the XRD patterns featured peaks due to the substrate $(\mathrm{Mg})$, magnesium oxide $(\mathrm{MgO})$, and the $\mathrm{Mg} 17 \mathrm{Sr} 2$ secondary phase. In PEO, the crystalline phase $\mathrm{MgO}$ forms due to anodic electrochemical processes inclusive of the oxidation of magnesium to $\mathrm{Mg2}+$ and its interaction with the oxygen ions that are produced during the electrolysis of the aqueous calcium-phosphate electrolyte. We note that the XRD analysis did not show the presence of $\mathrm{Ca}$ - and P-containing crystalline phases in the coatings, possibly due to the low content of these phases in the coatings or the presence of amorphous forms of calcium phosphate. 


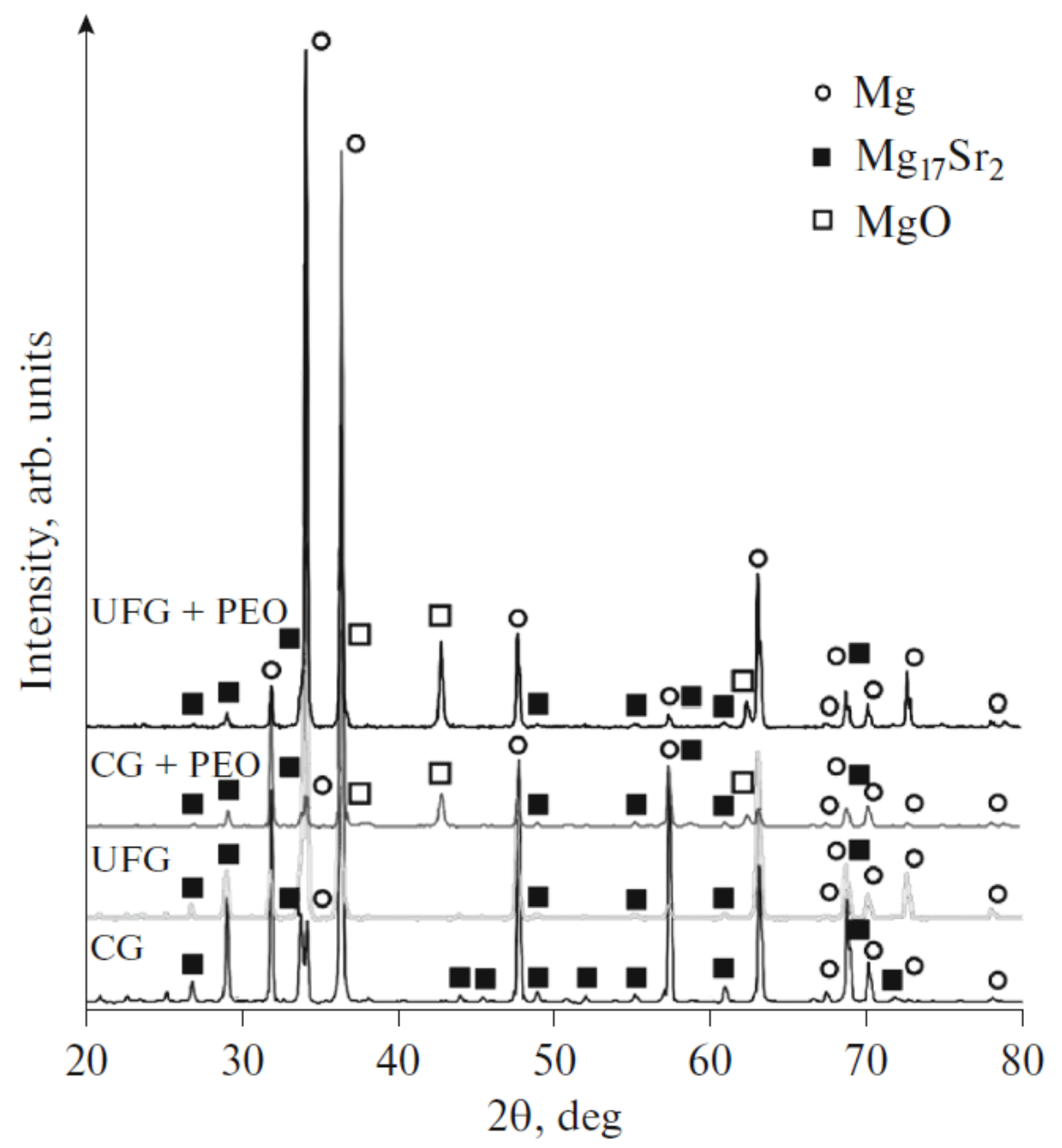

Fig. 6. XRD patterns of coating-free (CG and UFG) and coated (CG + PEO and UFG + PEO) samples.

\section{Electrochemical Testing}

Figure 7 shows the time-dependent variations of the open circuit potential and polarization curves recorded during the electrochemical corrosion tests of the uncoated CG and UFG samples, as well as their coated counterparts (i.e., CG + PEO and UFG + PEO). As can be seen for the uncoated samples (Fig. 7a), the open circuit potential reached a stable value within $2 \mathrm{~h}$ on average. After the uncoated samples were submerged into a Ringer's solution, their open circuit potential was increasing for the first 20 min possibly due the growth of a surface oxide film as a result of the electrochemical interaction between the substrate and the solution. Subsequently, the open circuit potential stabilized at around -1.57 to $-1.58 \mathrm{~V}$, suggesting that the surface of the uncoated samples was passivated by the corrosion products. The corrosion potential of the coated samples exhibited some oscillatory behaviour before reaching a stable value. Such oscillations may result from the Ringer's solution reaching the substrate surface through the pores in the coating. The electrochemical interaction between the substrate and the solution leads to an accumulation of the corrosion products within the pores in the coating, passivation of the surface of the coated samples, and stabilization of the corrosion potential. 

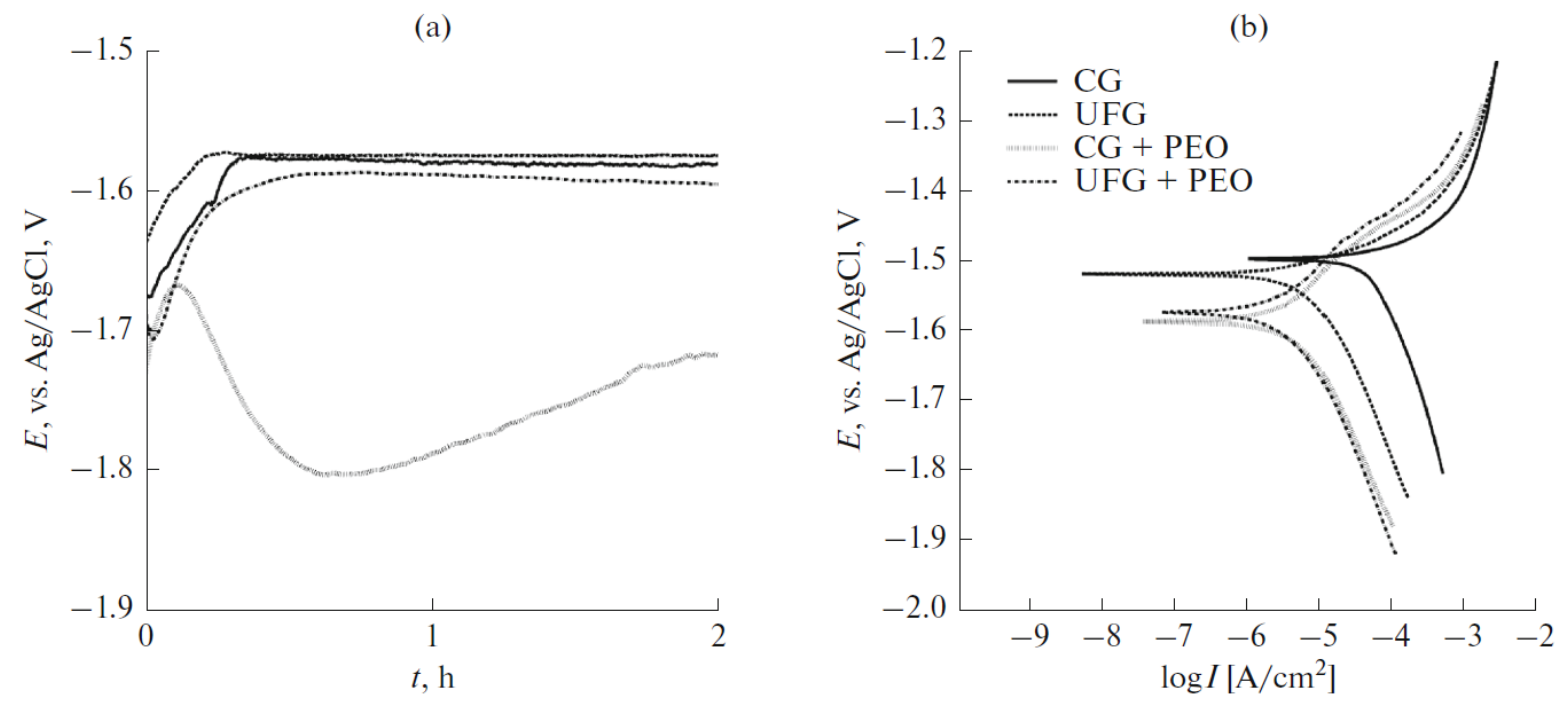

Fig. 7. Electrochemical testing of the prepared alloy samples: (a) corrosion potential and (b) polarization curves.

The parameters characterizing the corrosion resistance of the samples-corrosion potential Ecorr, corrosion current density icorr, and polarization resistance $R p$-were found from the polarization curves shown in Fig. 7b. The results are summarized in Table 4. It can be seen (Fig. 7b) that the anodic branches of the polarization curves are shifted insignificantly with respect to each other and they nearly coincide at potentials further from the corrosion potential, suggesting that the modification of the surface and structure of the samples does not affect their corrosion behavior in the area of the anodic branch. The slope of the cathodic branches is the same for all the samples, but the structural modification and the PEO treatment applied resulted in the cathodic branch shifting towards lower current densities, and, as a consequence, the corrosion potential decreases. The constancy of the cathodic branch slopes shows that the kinetics of the associated cathodic corrosion processes does not change, and the shift indicates that the surface area available for the cathodic reaction has changed. The sample UFG + PEO exhibits the least corrosion current icorr (Table 4), which indicates the best corrosion resistance. For all the samples, polarization resistance $R p$ was calculated from polarization curves near the corrosion potential. The sample UFG + PEO has the highest polarization resistance, which is consistent with the smallest corrosion current observed for this sample.

Table 4. Calculated corrosion parameters

\begin{tabular}{l|c|c|c|c}
\hline \multicolumn{1}{c|}{ Sample } & $E_{\text {corr }}, \mathrm{V}$ & $i_{\text {corr }}, \mu \mathrm{A} / \mathrm{cm}^{2}$ & $R_{\mathrm{p}}, \Omega \mathrm{cm}^{2}$ & $R_{\mathrm{c}}, \Omega \mathrm{cm}^{2}$ \\
\hline CG & $-1.51 \pm 0.015$ & $54.7 \pm 7.4$ & $202 \pm 58$ & $167 \pm 45$ \\
UFG & $-1.53 \pm 0.015$ & $6.5 \pm 3.4$ & $2450 \pm 368$ & $2397 \pm 405$ \\
CG + PEO & $-1.60 \pm 0.009$ & $4.6 \pm 2.7$ & $5240 \pm 950$ & $4843 \pm 847$ \\
UFG + PEO & $-1.58 \pm 0.01$ & $3.2 \pm 2.5$ & $7100 \pm 1082$ & $5387 \pm 982$ \\
\hline
\end{tabular}

The results of the EIS measurements (Nyquist and Bode plots) are shown in Fig. 8. The Nyquist plots, in the upper half-plane, feature two joint semicircles with different radii, which tell us that two relaxation electrochemical processes occur. In the lower halfplane of the impedance spectrum, all the samples display an inductive behavior in the low-frequency range. In addition, at very low frequencies, the UFG sample displays unusual behavior of the impedance variation different from the other samples. Instead of decreasing, the impedance increases notably, which suggests that the 
sample has higher corrosion resistance. The negative value for the time constant in the region of the inductive response has been confirmed in many repeated experiments; the investigation of this effect is beyond the scope of this work.

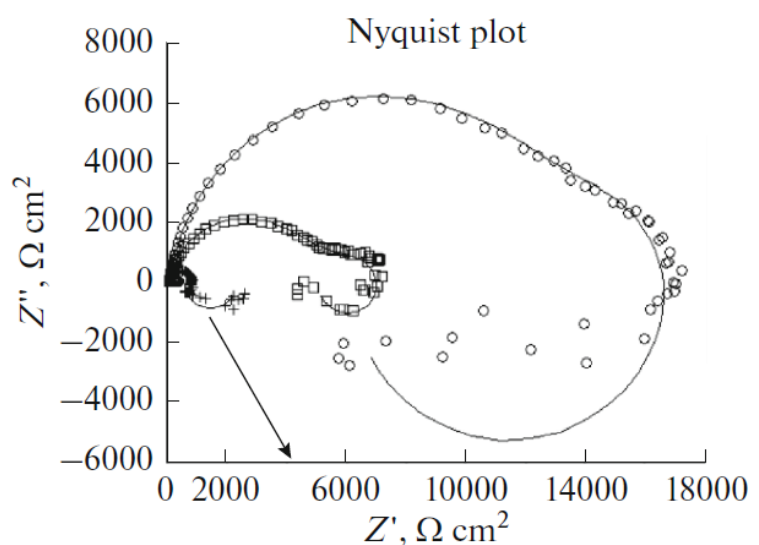

Bode plot
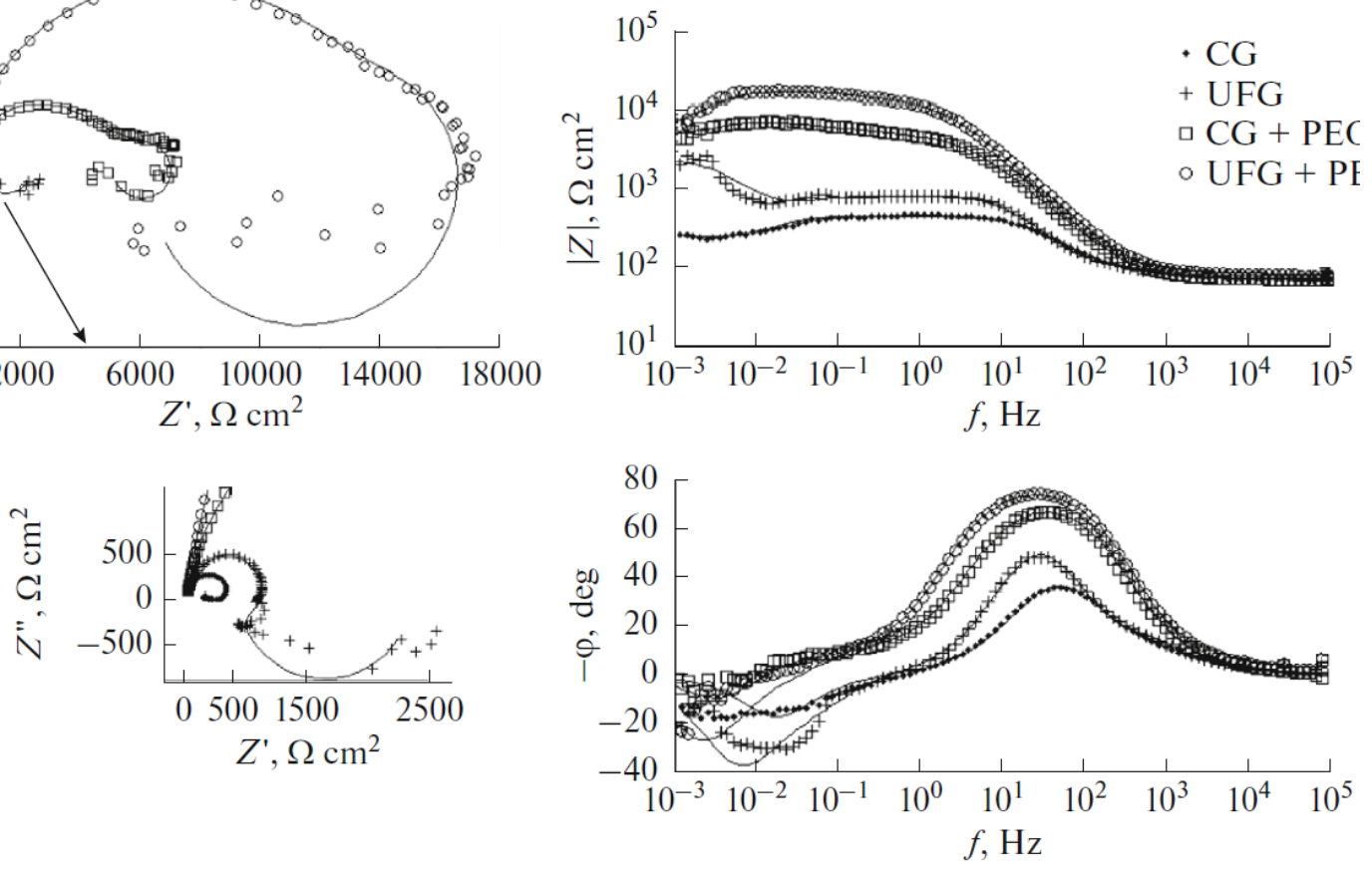

Fig. 8. Nyquist and Bode plots for the investigated samples.

The impedance data were modeled using equivalent circuits. The EIS data for samples CG, CG + PEO, and UFG + PEO were modeled with the circuit shown in Fig. 9a, and the UFG sample was modelled with the circuit shown in Fig. 9b. The results of modeling, i.e., values for parameters of the equivalent circuits, are summarized in Table 5.

(a)

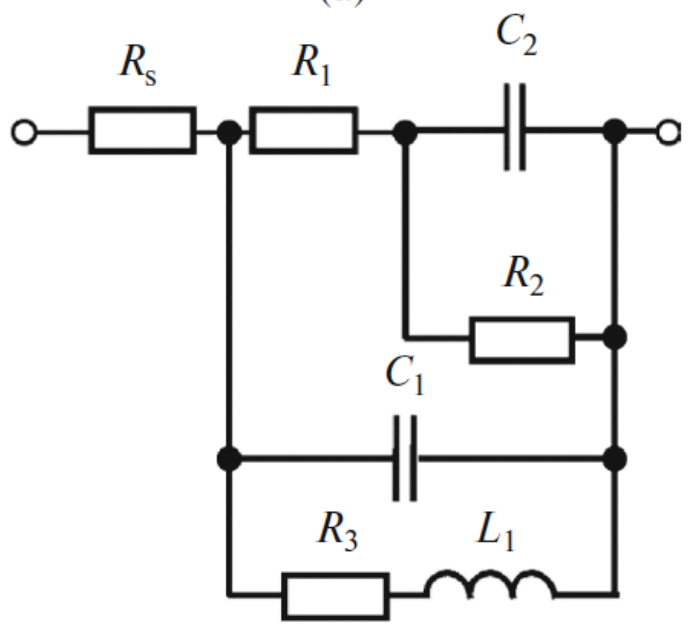

(b)

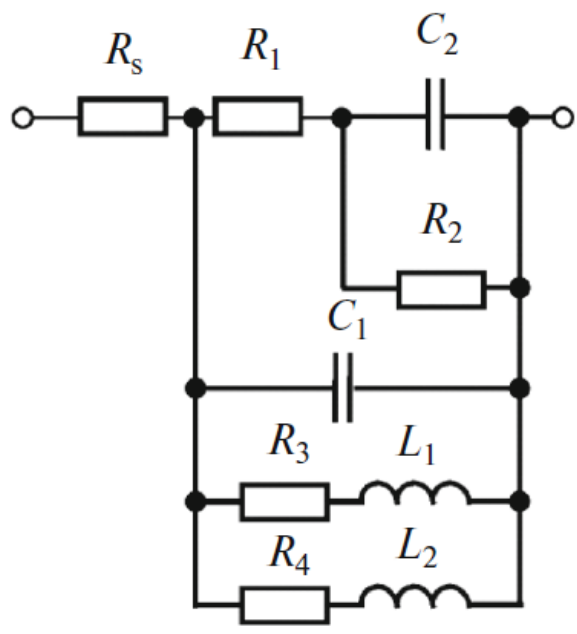

Fig. 9. Equivalent circuits modeling EIS measurements for the alloy samples: (a) CG, CG + PEO, UFG + PEO, and (b) UFG. 
Table 5. Equivalent circuit parameters

\begin{tabular}{|c|c|c|c|c|c|c|c|c|c|}
\hline & $\begin{array}{c}R_{\mathrm{s}}, \\
\Omega \mathrm{cm}^{2}\end{array}$ & $\begin{array}{c}R_{1}, \\
\Omega \mathrm{cm}^{2}\end{array}$ & $\begin{array}{c}R_{2}, \\
\Omega \mathrm{cm}^{2}\end{array}$ & $\begin{array}{c}R_{3}, \\
\Omega \mathrm{cm}^{2}\end{array}$ & $\begin{array}{c}C_{1}, \\
\mathrm{Fcm}^{-2}\end{array}$ & $\begin{array}{c}C_{2}, \\
\mathrm{~F} \mathrm{~cm}^{-2}\end{array}$ & $\begin{array}{c}L_{1}, \\
\mathrm{H} \mathrm{cm}^{2}\end{array}$ & $\begin{array}{c}R_{4}, \\
\Omega \mathrm{cm}^{2}\end{array}$ & $\begin{array}{c}L_{2}, \\
\mathrm{H} \mathrm{cm}^{2}\end{array}$ \\
\hline LG & $73.27 \pm 0.90$ & $77.31 \pm 6.06$ & $295.30 \pm 4.82$ & $305.10 \pm 13.94$ & $\begin{array}{l}7.7 \times 10^{-6} \pm \\
2.66 \times 10^{-7}\end{array}$ & $\begin{array}{c}1.65 \times 10^{-5} \pm \\
4.99 \times 10^{-7}\end{array}$ & $\begin{array}{l}4637 \pm \\
304.76\end{array}$ & - & - \\
\hline UFG & $71.92 \pm 1.15$ & $63.62 \pm 9.16$ & $668.30 \pm 16.02$ & $2558 \pm 275.55$ & $\begin{array}{c}6.48 \times 10^{-6} \pm \\
7.58 \times 10^{-7}\end{array}$ & $\begin{array}{c}1.48 \times 10^{-5} \pm \\
8.72 \times 10^{-7}\end{array}$ & $\begin{array}{l}10181 \pm \\
2489.7\end{array}$ & $\begin{array}{c}-760.4 \pm \\
22.54\end{array}$ & $\begin{array}{l}8672 \pm \\
625.54\end{array}$ \\
\hline $\mathrm{LG}+\mathrm{PEO}$ & $74.48 \pm 0.97$ & $4685 \pm 78.25$ & $2155 \pm 131.53$ & $17537 \pm 3114.1$ & $\begin{array}{c}6.86 \times 10^{-6} \pm \\
1.13 \times 10^{-7}\end{array}$ & $\begin{array}{l}34 \times 10^{-5} \pm \\
5.16 \times 10^{-5}\end{array}$ & $\begin{array}{c}1.34 \times 10^{6} \pm \\
2.18 \times 10^{5}\end{array}$ & - & - \\
\hline $\mathrm{UFG}+\mathrm{PEO}$ & $76.64 \pm 1.23$ & $11586 \pm 348.22$ & $3663 \pm 329.69$ & $13767 \pm 1414.2$ & $\begin{array}{l}5.05 \times 10^{-} \pm \\
58.52 \times 10^{-8}\end{array}$ & $\begin{array}{l}18 \times 10^{-5} \pm \\
4.04 \times 10^{-5}\end{array}$ & $\begin{array}{c}1.54 \times 10^{6} \pm \\
1.32 \times 10^{5}\end{array}$ & - & - \\
\hline
\end{tabular}

The physical meaning of the parameters for the two equivalent circuits (Fig. 9) is as follows. The circuit element $R$ s corresponds to the solution resistance, and elements $R 1$ and $C 1$ correspond, respectively, to the resistance and capacitance of the coating that has its pores filled with the Ringer's solution. The branch $R 2-C 2$ describes the charge transfer during corrosion processes, with element $R 2$ corresponding to the charge transfer resistance and element $C 2$ corresponding to the electrical double layer capacitance at the interface between the barrier layer and the electrolyte.

The circuit branch $R 3-L 1$ describes the formation of the corrosion products at the interface of "alloy -electrolyte" system for the unprocessed alloys, while for the coated alloys it is the "alloy-coatingelectrolyte" system. For all the samples, the values for inductance $L 1$ were very different from those of inductances in electrical engineering (Table 5), which is due to its formal use in EIS, where the inductance element represents the slow processes of adsorption and gas evolution, which gives rise to current with some delay after the voltage is applied, and this generates the positive phase shift between the test sinusoids.

The equivalent circuit for the UFG sample (Fig. 9b) contains the branch $R 4-L 2$ with a negative value for $R 4$, which may be related to an inverse slope of its current-voltage curve, i.e., the current through the system is decreased as the applied voltage is raised. The increase in the impedance at the lowest frequencies for the UFG sample can be explained as follows. The element $\mathrm{Sr}$ is distributed in the $\mathrm{Mg}-2 \% \mathrm{Sr}$ alloy along grain boundaries in the form of the Mg17Sr2 secondary phase, as shown in Fig. 10. In the alloy, the corrosion firstly attacks the grain boundaries with their Mg17Sr2 secondary phase, because in the electrochemical series magnesium is a less active metal than strontium. Therefore, for the sample with CG structure, the corrosion processes rapidly propagate along the grain boundaries and into the alloy bulk, and thus the secondary phase acts as a pathway of the alloy corrosion. By contrast with the CG sample, the secondary phases in its counterpart with UFG structure are distributed uniformly throughout the alloy bulk and are spatially separated from each other, which gives rise to an increase in impedance at the lowest EIS frequencies because a fraction of the surface is blocked by low soluble reaction products.

With the equivalent circuits, for all the samples, we were able to calculate corrosion resistance $R \mathrm{c}$ as the circuit resistance at the zero frequency, which, similarly to the polarization resistance $R p$, is a measure of the corrosion rate [11]. As it is known from the theory of electrical circuits, the impedance of a capacitive element is infinite at the zero frequency and that of an inductance element is zero [12]. Therefore, in calculating the input resistance of the equivalent circuit, we take the circuit branches containing capacitive elements open, while those containing inductive elements shorted. The results of calculations of $R c$ are given in Table 4 . It can be seen (Table 4 ) that the calculated values for $R c$ correspond, within an order of magnitude, to the values of the polarization 
resistance, and they exhibit the same pattern. This observation suggests that the parameters of the equivalent circuits used to model the EIS data for the samples under study were evaluated correctly.

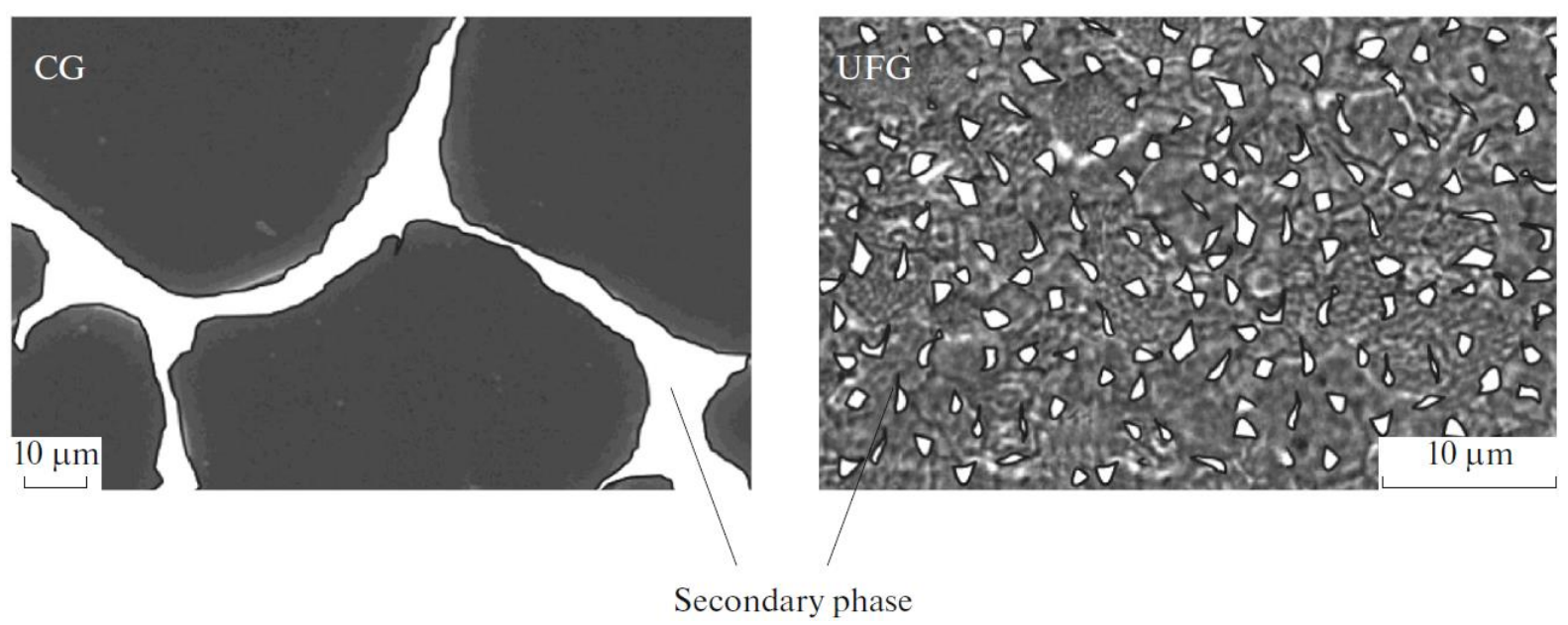

Fig. 10. Illustration of the distribution of Mg17Sr2 secondary phase in alloy samples with CG and UFG structures.

As a result, we showed that the corrosion properties of the $\mathrm{Mg}-2 \% \mathrm{Sr}$ alloy can be improved by reducing the grain size of the alloy structure using HPT, subjecting it to thermal annealing, and finally creating a PEO coating at its surface, with the improvement related, among other factors, to the kinetics of the PEO coating formation.

\section{CONCLUSIONS}

We carried out a quantitative evaluation of the kinetics of the PEO coating growth on CG and UFG samples of the biodegradable $\mathrm{Mg}-2 \% \mathrm{Sr}$ alloy; and the corrosion-protective properties of the fabricated coatings were investigated. Transient processes in the current density were studied chronoamperometrically, and the kinetic parameters characterizing the coating growth process were calculated using the dissolution/deposition model. The differences between kinetics parameters depending on the alloy structure and their correlation with the coating properties are demonstrated. The growth rate of the coating is higher, and the resulting coating is thicker, for the UFG sample than for its CG counterpart, provided the processing time is the same. The PEO coatings formed on the samples with CG and UFG structures have a developed porous surface, their morphology being independent of the substrate grain size. The electrochemical tests performed on the uncoated samples showed that a reduction in the alloy grain size leads to a decrease in the corrosion current density by an order of magnitude, while the corrosion and polarization resistances increase by the same amount. Due to the PEO coatings, the corrosion resistance of the $\mathrm{Mg}-2 \% \mathrm{Sr}$ alloy doubled, with the coating fabricated on UFG sample exhibiting the least corrosion current density and the highest corrosion resistance. The results of the study showed that the modification of $\mathrm{Mg}-2 \% \mathrm{Sr}$ alloy by reducing its grain size (i.e., creating the UFG structure) and followed by the PEO coating forms a promising technology for production of biodegradable traumatology implants. 
This research is supported by Russian Science Foundation (project No. 17-79-10144).

\section{REFERENCES}

1. Gu, X.N., Xie, X.H., Li, N., Zheng, Y.F., et al., Acta Biomater., 2012, vol. 8, no. 6, pp. 2360-2374.

2. Carboneras, M., Garsia-Alonso, M.C., and Escudero, M.L., Corros. Sci., 2011, vol. 53, pp. 14331439.

3. Zhao, D., Witte, F., Lu, F., Wang, J., Li, J., and Qin, L., Biomaterials, 2017, vol. 112, pp. 287-302.

4. Suminov, I.V., Belkin, P.N., Epel'del'd, A.V., Lyudin, V.B., et al., Plazmenno-elektroliticheskoe modifitsirovanie poverkhnosti metallov i splavov (Plasma-Electrolytic Modification of Surfaces of Metals and Alloys), Moscow: Tekhnosfera, 2011, in 2 vols.

5. Kulyasova, O.B., Islamgaliev, R.K., Parfenov, E.V., Zheng, Y.F., et al., IOP Conf. Ser.: Mater. Sci. Eng., 2018, vol. 380, p. 012014.

6. Gao, Y., Yerokhin, A., Parfenov, E., and Matthews, A., Electrochim. Acta, 2014, vol. 149, pp. 218230.

7. Scully, J.R., Corrosion, 2000, vol. 56, no. 2, pp. 199-218.

8. Damaskin, B.B., Petrii, O.A., and Tsirlina, G.A., Elektrokhimiya (Electrochemistry), Moscow: Khimiya, 2006, 2nd ed.

9. Snizhko, L.O., Yerokhin, A., Gurevina, N.I., Misnyankin, D.O., et al., Surf. Coat. Technol., 2010, vol. 205, pp. 1527-1531.

10. Parfenov, E.V., Nev'yantseva, R.R., Gorbatkov, S.A., and Erokhin, A.L., Elektrolitno-plazmennaya obrabotka: modelirovanie, diagnostika, upravlenie (Electrolytic- Plasma Processing: Modeling, Diagnostics, and Control), Moscow: Mashinostroenie, 2014.

11. King, A.D., Birbilis, N., and Scully, J.R., Electrochim. Acta, 2014, vol. 121, pp. 394-406.

12. Bessonov, L.A., Theoretical Basis of Electrical Engineering (Theory of Electrical Engineering. Electrical Circuits), Moscow: Gardariki, 2007. 